\title{
Noninvasive Ventilation for Critically Ill Subjects With Acute Respiratory Failure in the Emergency Department
}

\author{
Neha N Goel, Clark Owyang, Shamsuddoha Ranginwala, George T Loo, Lynne D Richardson, \\ and Kusum S Mathews
}

\begin{abstract}
BACKGROUND: We aimed to investigate the association between noninvasive ventilation (NIV) initiated in the emergency department and patient outcomes for those requiring invasive mechanical ventilation so that we could understand the effect of extended NIV use (ie, $>4 \mathrm{~h}$ ) prior to invasive mechanical ventilation on patient outcomes. METHODS: We conducted a retrospective single-center cohort study at an academic tertiary care hospital center. All emergency department patients with acute respiratory failure requiring invasive mechanical ventilation and admission to the ICU within $48 \mathrm{~h}$ of initial presentation over a 24-month period were included. RESULTS: Subject characteristics, ventilator parameters, and clinical course were captured via electronic query, respiratory billing data, and standardized chart abstraction. A total of 431 subjects with acute respiratory failure requiring invasive mechanical ventilation within 48 h of arrival were identified, of whom $115(26.7 \%)$ were exposed to NIV prior to invasive mechanical ventilation, with a median duration of $4 \mathrm{~h}$ (interquartile range 1.9-9.3). Based on a multivariable model controlling for covariates, any NIV exposure prior to invasive mechanical ventilation was not associated with an increased odds of persistent organ dysfunction or death. However, in the subset of subjects exposed to NIV, extended NIV use (ie, $>4 \mathrm{~h}$ ) prior to invasive mechanical ventilation was associated with increased odds of persistent organ dysfunction or death (odds ratio 4.11, 95\% CI 1.51-11.19). Extended NIV use was also associated with increased odds of in-hospital mortality (odds ratio 4.02, 95\% CI 1.51-10.74). CONCLUSIONS: Although any exposure to NIV prior to invasive mechanical ventilation did not appear to affect morbidity and mortality, extended NIV use prior to invasive mechanical ventilation was associated with worse patient outcomes, suggesting a need for additional study to better understand the ramifications of duration of NIV use prior to failure on outcomes. Given this early timeframe for intervention, future studies should be collaborations between the emergency department and ICU. Key words: emergency department; critically ill; noninvasive ventilation; bi-level; respiratory failure; mechanical ventilation. [Respir Care 2020;65(1):82-90. () 2020 Daedalus Enterprises]
\end{abstract}

Introduction

Noninvasive ventilation (NIV) has been increasingly employed in the emergency department and critical care set-

\footnotetext{
Drs Goel and Mathews are affiliated with the Division of Pulmonary, Critical Care, and Sleep Medicine, Department of Medicine; Drs Owyang, Loo, Richardson, and Mathews are affiliated with the Department of Emergency Medicine; Mr Ranginwala is affiliated with the Department of Respiratory Therapy; and Drs Loo and Richardson are affiliated with the Department of Population Health Science and Policy, Icahn School of Medicine at Mount Sinai, New York, New York.
}

Dr Goel presented a version of this paper was presented at the American tings for a number of conditions, including acute hypoxemic respiratory failure, pneumonia, and asthma, despite conflicting evidence for its utility in these disease states. ${ }^{1-4}$ NIV has been shown to be an efficacious treatment modality for patients with acute respiratory failure secondary to COPD or acute decompensated congestive heart failure, with improved survival and reduced need for invasive mechanical ventilation. ${ }^{5-7}$ However, recent studies in the ICU setting have reported that NIV can be harmful, with increased risk of mortality for acute hypoxemic respiratory

Thoracic Society 2018 International Conference, held May 18-23, 2018, in San Diego, California. 
failure, when compared to other forms of oxygen delivery such as high-flow oxygen. 8,9

Regardless of the indication, NIV use prior to invasive mechanical ventilation can sometimes lead to intubation-related complications and delays in invasive mechanical ventilation initiation. ${ }^{4}$ For patients with ARDS, delays in invasive mechanical ventilation initiation have been associated with a worse prognosis despite a lower severity of illness at presentation. ${ }^{10}$ Even within the COPD population, there is a growing subgroup who seem to have an increased mortality risk when treated with NIV prior to invasive mechanical ventilation compared to patients who are immediately intubated. ${ }^{8,11}$ A recent analysis of the LUNG-SAFE cohort explored the utilization of NIV in the ARDS population and reported that NIV failure, defined as the need for invasive mechanical ventilation after $2 \mathrm{~d}$ of NIV use, was associated with a higher mortality. ${ }^{12}$ Other studies examining delays in invasive mechanical ventilation initiation have also defined these intervals as $>2 \mathrm{~d}$ after presentation with respiratory failure, but the potential effect of shorter exposures to NIV prior to intubation, specifically timeframes more relevant to an emergency department setting, has not been evaluated.

These prior studies also focused on subject cohorts receiving NIV in an ICU setting, which is a more controlled and monitored setting than an emergency department or a medical floor. ${ }^{4,9,13,14}$ The majority of critically ill patients in respiratory distress present to an emergency department, where treatment decisions on NIV use or invasive mechanical ventilation initiation are made in the rapid context of resuscitation and stabilization. ${ }^{15,16}$ However, only one small trial has evaluated an emergency department-based subject cohort, reporting an increase in mortality associated with NIV failure, which was defined as the need for invasive mechanical ventilation despite NIV use. ${ }^{17}$ To adequately assess the outcomes of NIV failure, it is essential

Dr Goel is partially supported by National Institutes of Health (NIH) National Heart, Lung, and Blood Institute Award DHHS - 1T32 HL129974-PI: Richardson. Dr Mathews is partially supported by NIH National Heart, Lung, and Blood Institute Award 1K23HL130648-PI: Mathews. This work was supported in part through the Mount Sinai Data Warehouse resources and staff expertise provided by Scientific Computing at the Icahn School of Medicine at Mount Sinai. The other authors have disclosed no conflicts of interest.

Supplementary material related to this paper is available at http:// www.rcjournal.com.

Correspondence: Neha N Goel MD, Icahn School of Medicine at Mount Sinai, One Gustave L Levy Place, Box 1232, New York, NY 10029. E-mail: neha.goel@mountsinai.org.

DOI: $10.4187 /$ respcare. 07111

\section{QUICK LOOK}

\section{Current knowledge}

Recent studies have shown that failure of noninvasive ventilation (NIV) requiring invasive mechanical ventilation is associated with increased risk of mortality. Current evidence comes from subject cohorts enrolled and managed in the ICU, which is a vastly different care setting than the emergency department, where NIV is also utilized liberally. The outcomes of patients with NIV failure initiated and managed in the emergency department are unknown.

\section{What this paper contributes to our knowledge}

NIV was initiated in a very heterogeneous population in the emergency department, and its use was not limited to hypercapnic respiratory failure. Any exposure to NIV prior to failure was not associated with worse subject outcomes; however, extended use of NIV in the emergency department (ie, $>4 \mathrm{~h}$ ) was associated with increased risk of morbidity and mortality.

to consider patient characteristics and NIV utilization from the beginning of the patient's course, starting in the emergency department.

In this retrospective cohort study of critically ill emergency department subjects requiring invasive mechanical ventilation for respiratory failure, we first sought to assess if any emergency department-based NIV exposure prior to intubation was associated with deleterious effects downstream compared to subjects without any exposure to NIV (ie, those intubated directly). Second, our aim was to identify, only within those exposed to NIV, any association between duration of NIV exposure prior to intubation and deleterious downstream effects.

\section{Methods}

\section{Study Setting and Population}

This study included subjects presenting to a single, academic, urban, tertiary care center with a high-volume emergency department, which serves $>100,000$ visits annually and averages 300 visits a day. Given the increase in NIV use in the emergency department, our study specifically evaluated NIV delivered in the emergency department, where all of the NIV was initiated, titrated, and managed by the emergency department team, which consists of emergency medicine-trained house staff, faculty, and a respiratory therapist. This study site 
does not have a specified protocol or algorithm for NIV initiation, titration, or suspension; and all decisions regarding NIV use were made independently by the bedside team.

All adult patients (age $\geq 18 \mathrm{y}$ ) presenting to the emergency department from July 1, 2014, to June 30, 2016, who underwent invasive mechanical ventilation initiation and ICU admission within $48 \mathrm{~h}$ of presentation were included in the cohort. Patients were excluded if they had a do not intubate code status on presentation; were not accepted to the ICU within $48 \mathrm{~h}$ of presentation; presented from an outside hospital; had invasive ventilation primarily for an out-of-hospital cardiac arrest, chronic use of invasive ventilation, or airway protection for neurological pathology (intoxication, stroke, intracranial hemorrhage, or seizures).

\section{Study Design and Measurements}

For this retrospective cohort study, subject characteristics and clinical course were extracted from the electronic medical record, respiratory billing data, and standardized chart abstraction. Electronically collected data were validated and further expanded with standardized chart abstraction by trained reviewers.

The primary outcome of our study was a composite aimed to capture both patient morbidity and mortality by the presence of persistent organ dysfunction or death $(\mathrm{POD}+\mathrm{D})$ at $28 \mathrm{~d}$, defined as in-hospital mortality, discharge to hospice facility with mortality at $28 \mathrm{~d}$, or persistent use of vasopressors, new initiation of dialysis, or mechanical ventilation by day 28 of hospitalization. ${ }^{18}$ Secondary outcomes included in-hospital mortality and need for tracheostomy placement.

Subject-level data included age, gender, race/ethnicity, body mass index, severity of illness calculation using the Mortality Probability Model III scores on ICU admission $\left(\mathrm{MPM}_{0}-\mathrm{III}\right){ }^{19}$ revised Charlson comorbidity index, ${ }^{20}$ location of intubation, and emergency department acute lung injury prediction score (a score of $\geq 5$ was defined as having an increased risk for ARDS). ${ }^{21}$ The initial and subsequent NIV settings, timing and location of invasive mechanical ventilation initiation, and treatment duration of both types of ventilation were obtained. Additional variables regarding the subject's course, such as the primary indication for intubation and reason for respiratory failure, were also extracted. Reasons for intubation and respiratory failure were determined by the reasons cited in the intubation note or the primary provider note after intubation. The reasons for respiratory failure were hypoxemic respiratory failure, hypercapnic respiratory failure, altered mental status, shock, work of breathing, or mixed (ie, multiple reasons were cited for intubation, or respiratory failure).
Work of breathing was a subjective assessment for the reason for intubation, made by the primary bedside provider.

The cohort was divided into subjects who had emergency department-initiated NIV prior to invasive mechanical ventilation and those who were on invasive mechanical ventilation directly without any NIV exposure. Subgroup analyses of subjects with NIV exposure were conducted. The median duration of NIV use prior to invasive mechanical ventilation within the available data was used to divide the cohort into a brief exposure group (ie, $<4 \mathrm{~h}$ ) and an extended exposure group (ie, $\geq 4 \mathrm{~h}$ ). The duration of NIV use was determined by the bedside assessment of the primary team and respiratory therapist, occasionally in consultation with the ICU or pulmonary service team.

This study was approved by the institutional review board at the study site under an expedited review procedure, with a waiver of informed consent.

\section{Statistical Analysis}

Univariate analysis was conducted on continuous and categorical variables to determine their measures of central tendency (eg, mean, median, mode), frequency distribution, and standard deviation and interquartile range as appropriate. Baseline categorical characteristics were expressed as numbers and percentages, and these frequencies were tested using chi-square analysis. Continuous variables were expressed as medians with an interquartile range or as means with standard deviation as appropriate. Based on exposure to NIV and then by subclassification by the duration of NIV exposure as described above, baseline characteristics were compared between groups using Wilcoxon Mann-Whitney $U$ and independent $t$ tests as appropriate.

Bivariate analysis was used to assess subject variables as predictors for NIV use (Table 1). Predictors of NIV use were modeled using multivariable regression modeling. In the complete cohort, multivariable logistic regression modeling was used to determine the effect of any NIV exposure on $\mathrm{POD}+\mathrm{D}$ compared to direct invasive mechanical ventilation. In only the NIV-exposed group, the effect of NIV duration (ie, brief or extended) on POD $+\mathrm{D}$ was modeled, controlling for other covariates. The secondary outcome of in-hospital mortality, a component of POD $+\mathrm{D}$, but one of particular interest, was also separately modeled using multivariable regression modeling. Bivariate analyses of the other components of the composite outcome, such as vasopressor use, new initiation of dialysis, and mechanical ventilation at day 28 , were also conducted. Model fit was assessed using the Akaike information criterion and the Hosmer-Lemeshow goodness of fit test. Sensitivity analyses were performed by testing the inter- 
Table 1. Baseline Characteristics for Emergency Department Subjects on Invasive Mechanical Ventilation for Acute Respiratory Failure Within 48 Hours of Presentation

\begin{tabular}{|c|c|c|c|c|}
\hline Characteristic & Full Cohort & $\begin{array}{l}\text { Direct Mechanical } \\
\text { Ventilation }\end{array}$ & $\begin{array}{l}\text { Mechanical Ventilation After } \\
\text { NIV Exposure }\end{array}$ & $P^{*}$ \\
\hline Age, y & $64(54-75)$ & $62(53.5-72)$ & $69(56-78)$ & $<.001$ \\
\hline Body mass index, $\mathrm{kg} / \mathrm{m}^{2}$ & $29.0(23.9-43.2)$ & $26.5(22.7-30.9)$ & $57.0(47.8-66.1)$ & $<.001$ \\
\hline Gender & & & & .25 \\
\hline Female & $205(47.6)$ & $145(45.9)$ & $60(52.2)$ & \\
\hline Male & $226(52.4)$ & $171(54.1)$ & $55(47.8)$ & \\
\hline Race & & & & .002 \\
\hline Caucasian & $109(25.3)$ & $80(25.3)$ & $29(25.2)$ & \\
\hline African American & $131(30.4)$ & $91(28.8)$ & $40(34.8)$ & \\
\hline Hispanic & $119(27.6)$ & $87(27.5)$ & $32(27.8)$ & \\
\hline Other & $68(15.8)$ & $58(18.5)$ & $10(8.7)$ & \\
\hline Unknown & $4(1.0)$ & $0(0.0)$ & $4(3.5)$ & \\
\hline Insurance & & & & .01 \\
\hline Medicare or private payor & $289(67.1)$ & $199(63.0)$ & $90(78.3)$ & \\
\hline Medicaid & $114(26.5)$ & $94(29.8)$ & $20(17.4)$ & \\
\hline Other or unknown & $28(6.5)$ & $23(7.3)$ & $5(4.4)$ & \\
\hline Reason for intubation & & & & $<.001$ \\
\hline Hypercapnic respiratory failure & $107(24.8)$ & $52(16.5)$ & $55(47.8)$ & \\
\hline Hypoxemic respiratory failure & $110(25.5)$ & $75(23.7)$ & $35(30.4)$ & \\
\hline Altered mental status & $67(15.6)$ & $58(18.4)$ & $9(7.8)$ & \\
\hline Shock & $96(22.3)$ & $91(28.8)$ & $5(4.4)$ & \\
\hline Work of breathing & $39(9.1)$ & $31(9.8)$ & $8(7.0)$ & \\
\hline Mixed & $12(2.8)$ & $9(2.9)$ & $3(2.6)$ & \\
\hline Location of intubation & & & & .02 \\
\hline Emergency department & $316(73.3)$ & $242(76.6)$ & $74(64.4)$ & \\
\hline $\mathrm{ICU}$ & $78(18.1)$ & $48(15.2)$ & $30(26.1)$ & \\
\hline Floor & $37(8.6)$ & $26(8.2)$ & $11(9.6)$ & \\
\hline $\mathrm{MPM}_{0}$-III score & $17.4(8.6-33.2)$ & $14.9(7.6-30.6)$ & $24.0(14.3-39.5)$ & $<.001$ \\
\hline Revised Charlson comorbidity index & $2(1-5)$ & $2(1-5)$ & $2(2-5)$ & .76 \\
\hline Risk of ARDS $\dagger$ & $311(72.2)$ & $227(71.8)$ & $84(73.0)$ & .80 \\
\hline NIV exposure, $\mathrm{h}$ & NA & 0 & $4(1.9-9.3)$ & $<.001$ \\
\hline Time to intubation, $\mathrm{h}$ & $6.5(2.2-16.1)$ & $5.8(1.4-16.6)$ & $9.1(3.6-15.4)$ & .02 \\
\hline Hospital length of stay, $d$ & $10.5(5.8-19.2)$ & $10.1(5.5-19.0)$ & $10.9(7.0-22.1)$ & .22 \\
\hline ICU length of stay, d & $4.8(2.7-8.9)$ & $4.6(2.7-8.6)$ & $5.3(2.7-9.9)$ & .28 \\
\hline Days on ventilator, $d$ & $3.1(1.3-9.6)$ & $3.0(1.2-9.1)$ & $3.5(1.7-11.3)$ & .10 \\
\hline \multicolumn{5}{|c|}{$\begin{array}{l}\text { Data are presented as median (interquartile range) or } n(\%) \text {. Full cohort: } N=431 \text { subjects; Direct invasive ventilation: } n=316 \text { subjects; Invasive ventilation after NIV exposure: } n=115 \\
\text { subjects. } \\
\text { * Comparing prior exposure to NIV vs. no exposure. } \\
\dagger \text { Defined as Lung Injury Prediction Score } \geq 5 \text { in the emergency department. } \\
\text { MPM }_{0}-\text { III }=\text { mortality probability model on admission (severity of illness) }\end{array}$} \\
\hline
\end{tabular}

actions between $\mathrm{MPM}_{0}$-III and duration of NIV exposure because sicker patients might be more likely to be directly intubated. ${ }^{10,12,22} \mathrm{We}$ also tested for interactions between age and duration of NIV exposure to evaluate whether older patients might preferentially be trialed on less invasive therapies. ${ }^{23,24}$

The effects of the covariates on the outcomes were evaluated using a 2-tailed statistical test with significance of $P<.05$. The data analysis was generated using SAS 9.4 (SAS Institute, Cary, North Carolina).

\section{Results}

\section{Baseline Characteristics}

Within the study period, 1,432 emergency department patients were admitted to the ICU, of whom 699 (48.8\%) required intubation and invasive mechanical ventilation for acute respiratory failure within $48 \mathrm{~h}$ of presentation. Of these patients, 268 met exclusion criteria (supplemental figure; see the supplementary materials at http://www. rcjournal.com). Table 1 describes the cohort characteris- 
Table 2. Predictors of NIV Use in Critically Ill Emergency Department Subjects With Acute Respiratory Failure Requiring Invasive Mechanical Ventilation Within 48 Hours of Presentation

\begin{tabular}{|c|c|c|}
\hline Predictors & Odds Ratio $(95 \% \mathrm{CI})$ & $P$ \\
\hline Female (Reference: male) & $2.50(1.12-5.58)$ & .03 \\
\hline Body mass index, $\mathrm{kg} / \mathrm{m}^{2}$ & $1.16(1.13-1.20)$ & $<.001$ \\
\hline \multicolumn{3}{|l|}{ Race } \\
\hline Caucasian & Reference & \\
\hline African American & $0.59(0.21-1.61)$ & .30 \\
\hline Hispanic & $0.86(0.32-2.33)$ & .77 \\
\hline Other & $0.51(0.14-1.85)$ & .31 \\
\hline Unknown & $>999.9(<0.001$ to $>999.9)$ & .99 \\
\hline \multicolumn{3}{|l|}{ Reason for respiratory failure } \\
\hline Hypercapnic respiratory failure & Reference & \\
\hline Hypoxemic respiratory failure & $0.78(0.32-1.93)$ & .60 \\
\hline Altered mental status & $0.17(0.05-0.60)$ & .006 \\
\hline Shock & $0.06(0.01-0.27)$ & $<.001$ \\
\hline Work of breathing & $0.29(0.04-2.14)$ & .23 \\
\hline Mixed & $0.26(0.07-1.03)$ & .055 \\
\hline Risk of ARDS & $0.83(0.36-1.95)$ & .68 \\
\hline \multicolumn{3}{|c|}{$\begin{array}{l}\text { Results are from a multivariate regression model. AIC }=226.20 ; \text { Hosmer Lemeshow goodness of fit } P=.11 \\
\text { NIV = noninvasive ventilation } \\
\text { AIC = Akaike information criterion }\end{array}$} \\
\hline
\end{tabular}

tics ( $N=431$ subjects), stratified by those with and without NIV exposure prior to invasive mechanical ventilation ( $n=115,26.7 \%$; and $n=316,73.3 \%$, respectively). Compared to subjects who were on invasive mechanical ventilation directly, those exposed to NIV before invasive mechanical ventilation were older, had a higher body mass index, and higher severity of illness on admission to the ICU $\left(\mathrm{MPM}_{0}\right.$-III). The top 2 reasons for respiratory failure in subjects who were on invasive mechanical ventilation directly were shock (28.8\%) and hypoxemic respiratory failure (23.7\%) versus those exposed initially to NIV, whose respiratory failure was attributed to hypercapnic (47.8\%) and hypoxemic respiratory failure $(30.4 \%)$. Those with NIV exposure also had more total ventilator days than those on invasive mechanical ventilation directly. There were no significant differences between the groups in sex, risk for ARDS, and hospital and ICU lengths of stay.

Within the NIV-exposed group, 59.1\% $(n=68)$ were started on bi-level settings of inspiratory positive airway pressure (IPAP) $=10 \mathrm{~cm} \mathrm{H}_{2} \mathrm{O}$ and expiratory positive airway pressure (EPAP) $=5 \mathrm{~cm} \mathrm{H}_{2} \mathrm{O}$, of whom only $7.4 \%$ $(n=5)$ had documentation of settings titration. Of the remaining NIV cohort, $7 \%(n=8)$ were on CPAP only, $33.9 \%(n=39)$ were on varied settings of bi-level positive airway pressure, with IPAP ranging from $12-25 \mathrm{~cm} \mathrm{H}_{2} \mathrm{O}$ and EPAP ranging from 6-12 $\mathrm{cm} \mathrm{H}_{2} \mathrm{O}$. Median duration of NIV exposure prior to invasive mechanical ventilation was $4 \mathrm{~h}$ (interquartile range 1.9-9.3). The baseline characteristics of those with brief (53\%) and extended (47\%) NIV exposures are detailed in the appendix (see the sup- plementary materials at http://www.rcjournal.com). The characteristics were similar in both groups, except that more subjects in the extended exposure group were intubated in the ICU compared to the brief exposure group (44.4\% vs $9.8 \%, P<.001)$.

\section{Predictors of NIV Exposure and Association of NIV Exposure on POD+D}

Sex, body mass index, and type of respiratory failure requiring invasive mechanical ventilation were identified as strongly associated with increased likelihood of NIV use (Table 2). Race and an increased risk of ARDS were not predictors of NIV use. In a multivariate logistic regression model of the whole cohort, any NIV exposure was not associated with risk of $\mathrm{POD}+\mathrm{D}$ (odds ratio 1.60, 95\% CI 0.66-3.87) (appendix; see the supplementary materials at http://www.rcjournal.com). In an exploratory analysis modeling the association between number of hours of NIV exposure prior to invasive mechanical ventilation on $\mathrm{POD}+\mathrm{D}$, there was a small trend toward increased risk of $\mathrm{POD}+\mathrm{D}$ with longer exposure to NIV use (odds ratio 1.06, 95\% CI 0.996-1.12).

\section{Association of Prolonged NIV and POD+D}

Within the group exposed to NIV, a covariate-adjusted model showed that extended NIV exposure was associated with a higher likelihood of $\mathrm{POD}+\mathrm{D}$ compared to those with brief exposure prior to intubation (odds ratio 4.11, 


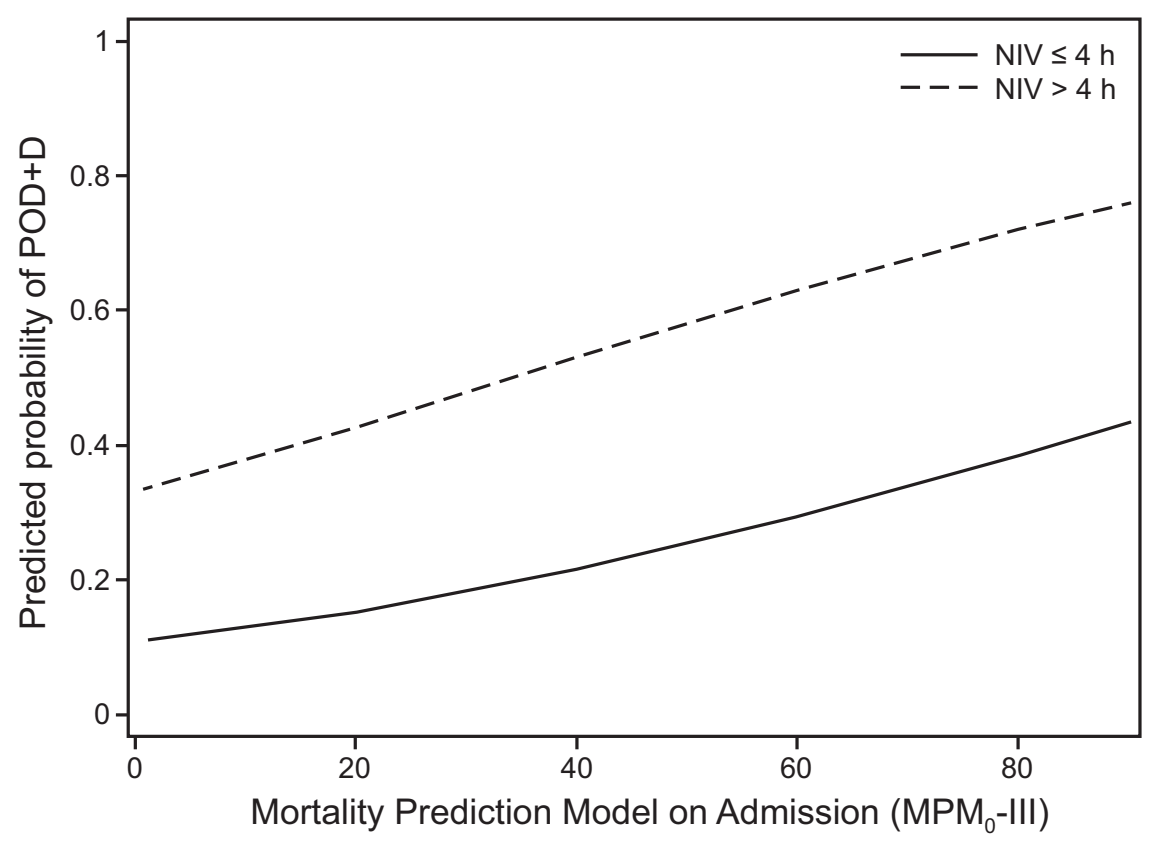

Fig. 1. Predicted probability of persistent organ dysfunction and death (POD+D) by the Mortality Probability Model on Admission (MPM $\left.\mathrm{M}_{0}-\mathrm{III}_{\mathrm{I}}\right)$ stratified by those who were exposed to noninvasive ventilation (NIV) for $\leq 4 \mathrm{~h}$ or $>4$ period prior to invasive mechanical ventilation. In this cohort of critically ill emergency department subjects requiring invasive ventilation for acute respiratory failure, $>4 \mathrm{~h}$ exposure to NIV was associated with an increase in the odds of dying or having significant morbidity during hospitalization. The POD $+\mathrm{D}$ model was adjusted for age, race, reason for respiratory failure, MPM - -III score, risk of ARDS, and days on mechanical ventilation.

95\% CI 1.51-11.19) (appendix; see the supplementary materials at http://www.rcjournal.com). The increased odds of $\mathrm{POD}+\mathrm{D}$ associated with extended exposure to NIV remained prominent through all severities of illness (Figure 1). Sensitivity analyses showed no interaction between extended NIV exposure and $\mathrm{MPM}_{0}$-III mortality score or between extended NIV exposure and age (data not shown). Secondary analysis showed that extended exposure to NIV was associated with higher odds of in-hospital mortality (odds ratio $4.02,95 \%$ CI 1.51-10.74). There was no association between extended NIV use and need for tracheostomy placement (Table 3).

\section{Discussion}

Our results indicated no association between NIV failure (ie, any exposure to NIV prior to invasive mechanical ventilation) and morbidity and mortality; however, an extended exposure to NIV of $>4 \mathrm{~h}$ was associated with worse patient outcomes. It is important to identify thresholds at which we need to stop NIV and consider other therapies. ${ }^{25}$ While previous data indicate that failure of NIV leads to worse outcomes, ${ }^{12}$ our results indicate that not all NIV failures are equal: subjects with longer exposure to NIV prior to needing intubation have poorer outcomes. We chose to dichotomize our NIV exposure variable around the median to identify a practical point at which we might consider re-evaluation or intervention for
Table 3. Outcomes of Emergency Department Subjects With Acute Respiratory Failure Exposed to Brief NIV or Extended NIV Prior to Invasive Mechanical Ventilation Within 48 Hours of Presentation*

\begin{tabular}{lll}
\hline \hline Outcomes & Odds Ratio $(95 \% \mathrm{CI})$ & $P$ \\
\hline Predictors of POD+D $\dagger$ & $4.11(1.51-11.19)$ & .006 \\
Mortality at 28 d & $2.11(0.95-4.68)$ & .064 \\
Vasopressors at 28 d & $2.10(0.80-5.54)$ & .13 \\
Ventilator at 28 d & $1.20(0.55-2.61)$ & .65 \\
New dialysis at 28 d & $0.66(0.15-2.90)$ & .58 \\
In-hospital mortality $\neq$ & $4.02(1.51-10.74)$ & .006 \\
Tracheostomy placement§ & $0.23(0.004-14.33)$ & .78
\end{tabular}

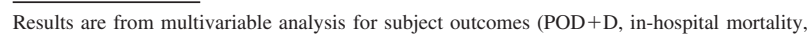
and tracheostomy placement) and from bivariate analysis of the components of POD $+\mathrm{D}$ composite score.

* Brief NIV exposure is $\leq 4 \mathrm{~h}$; extended NIV exposure is $>4 \mathrm{~h}$.

$\dagger$ Model 1 adjusted for age, race, reason for respiratory failure, MPM $_{0}$-III, ARDS risk, and ventilator days; $\mathrm{AIC}=141.94$, Hosmer Lemeshow goodness of fit $P=.95$.

$\$$ Model 2 adjusted for age, race, $\mathrm{MPM}_{0}$-III, ventilator days, and revised Charlson comorbidity index; $\mathrm{AIC}=134.45$, Hosmer Lemeshow goodness of fit $P=.83$.

$\S$ Model 3 adjusted for age, days on ventilator, length of stay, and revised Charlson comorbidity index; AIC $=15.95$; Hosmer Lemeshow goodness of fit $P=.94$. $\mathrm{NIV}=$ noninvasive ventilation

$\mathrm{POD}+\mathrm{D}=$ persistent organ dysfunction + death

$\mathrm{MPM}_{0}-\mathrm{III}=$ mortality probability model on admission (severity of illness)

AIC $=$ Akaike information criterion

future studies. Although our data indicate $4 \mathrm{~h}$ of exposure to NIV therapy as a potential time at which we need to consider re-evaluating a patient for continued NIV versus 
alternative therapies, larger prospective studies investigating the optimal threshold or time to intervention are needed.

The increase in mortality associated with NIV failure has been well established, but our understanding of why NIV failure occurs in some patients while others do well is still limited. ${ }^{26}$ Our aim in focusing solely on subjects with NIV failure earlier in their treatment course was to identify factors leading to NIV selection and to describe NIV utilization in these cases. Some of the factors associated with NIV use in our cohort are body mass index and respiratory failure secondary to altered mental status and shock. Our data conflict with previous literature reporting that body mass index $>25 \mathrm{~kg} / \mathrm{m}^{2}$ was associated with NIV success. ${ }^{27}$ However, that study was performed primarily in surgical subjects in the ICU setting. Our emergency department-based cohort was exposed to NIV at seemingly default settings of IPAP $10 \mathrm{~cm} \mathrm{H}_{2} \mathrm{O}$ and EPAP $5 \mathrm{~cm} \mathrm{H}_{2} \mathrm{O}$, which might not be sufficient in an obese population. Furthermore, unlike the ICU setting, where active NIV and invasive mechanical ventilation management by dedicated staff are standard, there was rarely any documented titration of the initial bi-level settings for our cohort in the emergency department. Prolonged exposure to NIV without actively setting titration could result in the undertreatment of patients in respiratory distress and could be a potential source of NIV failure leading to poor outcomes.

Although NIV is widely utilized, there is broad institutional variation. It is not always used for indications with the strongest evidence, by providers without adequate training on NIV management, or in sufficiently monitored settings. ${ }^{11,28-31}$ Studies with subject data limited to the ICU setting are less informative and thus less generalizable to the emergency department setting; more focused analysis of emergency department-based NIV use and its effect on downstream patient outcomes are needed. Additionally, higher rates of NIV failure are seen when NIV is utilized for conditions with weaker evidence for NIV benefit, such as pneumonia and asthma, ${ }^{31}$ as evidenced by the large number of subjects in our cohort treated with NIV for hypoxemic respiratory failure. For critically ill patients presenting to the emergency department, treatment decisions and subsequent care decisions are made by the emergency department team, under the pressure of time and often with limited information, and these conditions must be considered when evaluating reasons for poor outcomes associated with NIV failure.

Another consideration for NIV failure leading to adverse outcomes within our cohort are the low pressures used for the majority of the NIV users. The settings of IPAP $10 \mathrm{~cm} \mathrm{H}_{2} \mathrm{O}$ and EPAP $5 \mathrm{~cm} \mathrm{H}_{2} \mathrm{O}$ represent default settings at our institution, and these settings were used in the majority of the subjects without documented titration. The poor outcomes seen with prolonged NIV use may be more of a reflection of incorrectly titrated NIV and needs further study. However, with expanding NIV use in recent years, it is utilized globally and often without the supervision of trained personnel. Our study was specifically looking at NIV delivered in the emergency department because the use of NIV in this setting has been increasing and data regarding its utilization and efficacy are lacking. In clinical situations like ARDS, which are under-recognized even in the ICU, ${ }^{32,33}$ where delays in care can lead to morbidity and mortality, the development of structured guidelines for emergency department-based NIV utilization may be beneficial.

Some strengths of our study include the use of multimodal structured data extraction with high validity, which afforded more comprehensive insight into practice patterns in the emergency department. Despite the retrospective study design, we were able to elicit subject-level factors contributing to the decision-making around NIV initiation. The serial capture of emergency departmentbased NIV data and invasive mechanical ventilation practices assesses patients much earlier in the course of their respiratory failure, providing some insight into the timeline to consider for future trials regarding NIV use in respiratory failure. NIV management appears to be time sensitive, such that early identification of patients at risk for NIV failure may prevent adverse outcomes.

Limitations of our study include the lack of more accurate measures of quality and effective NIV use. Given the retrospective nature of the study, we only know the duration of NIV use and the settings used, but we have minimal data on subject adherence or the adequacy of the settings in terms of providing support, both of which can have a significant impact on the reason for failure and the decision to initiate invasive mechanical ventilation. While we utilized the revised Charlson comorbidity index and a severity of illness calculation with the mortality prediction model on admission in our analysis to account for some of the subjects' pre-morbid status, our models are underfit because we do not have the granularity in our data to assess individual patient respiratory function, pre-hospital care, mask choice when delivering NIV, or secretion care. We also have to consider the presence of selection bias associated with the decision to initiation NIV versus invasive mechanical ventilation, which is often incompletely documented in electronic medical records.

Our study also suggests that delays in intubation might lead to adverse events, perhaps indicating the need for intervention earlier in the patient's course when exposed to NIV. Prospective multi-center studies on exposure of NIV starting earlier in the patients' course in the emergency department might be crucial in determining when NIV needs to be stopped and alternative therapies considered. Another aspect of NIV utilization not captured in our data are the significant variations in practice that stem from a lack of consensus regarding the benefits of early 
invasive mechanical ventilation when noninvasive alternatives are present. Institutional and physician-related characteristics also factor into decisions surrounding NIV use and the initiation of invasive mechanical ventilation. ${ }^{34}$ Better understanding of predictors of NIV use and failure, especially in vulnerable populations such as those with weaker indications for NIV, might mitigate some of this variation of practice.

\section{Conclusions}

While any NIV exposure prior to intubation did not appear to affect subject morbidity and mortality, in subjects exposed to NIV, $>4 \mathrm{~h}$ of NIV exposure had a negative impact on subject outcomes, suggesting a need for improved and prompt recognition of NIV failure. While previous studies have reported that failure of NIV leading to intubation after $\geq 2 \mathrm{~d}$ is detrimental to patient outcomes, our data suggest that this happens sooner. The emergency department, where most of the patients with acute respiratory failure likely reside in the first $4 \mathrm{~h}$ of their hospital course, should be included in future studies of early recognition of NIV failure and treatment.

\section{REFERENCES}

1. Antonelli M, Conti G, Moro ML, Esquinas A, Gonzalez-Diaz G, Confalonieri M, et al. Predictors of failure of noninvasive positive pressure ventilation in patients with acute hypoxemic respiratory failure: a multi-center study. Intensive Care Med 2001;27(11):17181728.

2. Jolliet P, Abajo B, Pasquina P, Chevrolet JC. Non-invasive pressure support ventilation in severe community-acquired pneumonia. Intensive Care Med 2001;27(5):812-821.

3. Domenighetti G, Gayer R, Gentilini R. Noninvasive pressure support ventilation in non-COPD patients with acute cardiogenic pulmonary edema and severe community-acquired pneumonia: acute effects and outcome. Intensive Care Med 2002;28(9):1226-1232.

4. Meeder AM, Tjan DH, van Zanten AR. Noninvasive and invasive positive pressure ventilation for acute respiratory failure in critically ill patients: a comparative cohort study. J Thorac Dis 2016;8(5):813-825.

5. Masip J, Roque M, Sanchez B, Fernandez R, Subirana M, Exposito JA. Noninvasive ventilation in acute cardiogenic pulmonary edema: systematic review and meta-analysis. JAMA 2005;294(24):3124-3130.

6. Keenan SP, Sinuff T, Cook DJ, Hill NS. Which patients with acute exacerbation of chronic obstructive pulmonary disease benefit from noninvasive positive-pressure ventilation? A systematic review of the literature. Ann Intern Med 2003;138(11):861-870.

7. Lightowler JV, Wedzicha JA, Elliott MW, Ram FS. Non-invasive positive pressure ventilation to treat respiratory failure resulting from exacerbations of chronic obstructive pulmonary disease: Cochrane systematic review and meta-analysis. BMJ 2003;326(7382):185.

8. Chandra D, Stamm JA, Taylor B, Ramos RM, Satterwhite L, Krishnan $\mathrm{JA}$, et al. Outcomes of noninvasive ventilation for acute exacerbations of chronic obstructive pulmonary disease in the United States, 19982008. Am J Respir Crit Care Med 2012;185(2):152-159.

9. Frat JP, Thille AW, Mercat A, Girault C, Ragot S, Perbet S, et al. High-flow oxygen through nasal cannula in acute hypoxemic respiratory failure. N Engl J Med 2015;372(23):2185-2196.
10. Kangelaris KN, Ware LB, Wang CY, Janz DR, Zhuo H, Matthay MA, et al. Timing of intubation and clinical outcomes in adults with acute respiratory distress syndrome. Crit Care Med 2016;44(1):120-129.

11. Stefan MS, Nathanson BH, Higgins TL, Steingrub JS, Lagu T, Rothberg $\mathrm{MB}$, et al. Comparative effectiveness of noninvasive and invasive ventilation in critically ill patients with acute exacerbation of chronic obstructive pulmonary disease. Crit Care Med 2015;43(7):1386-1394.

12. Bellani G, Laffey JG, Pham T, Madotto F, Fan E, Brochard L, et al. Noninvasive ventilation of patients with acute respiratory distress syndrome: insights from the LUNG SAFE study. Am J Respir Crit Care Med 2017;195(1):67-77.

13. Schnell D, Timsit JF, Darmon M, Vesin A, Goldgran-Toledano D, Dumenil AS, et al. Noninvasive mechanical ventilation in acute respiratory failure: trends in use and outcomes. Intensive Care Med 2014;40(4):582-591.

14. Demoule A, Girou E, Richard JC, Taille S, Brochard L. Benefits and risks of success or failure of noninvasive ventilation. Intensive Care Med 2006;32(11):1756-1765.

15. Kelly AM, Holdgate A, Keijzers G, Klim S, Graham CA, Craig S, et al. Epidemiology, treatment, disposition and outcome of patients with acute exacerbation of COPD presenting to emergency departments in Australia and South East Asia: an AANZDEM study. Respirology 2018;23(7):681-686.

16. Antro C, Merico F, Urbino R, Gai V. Non-invasive ventilation as a first-line treatment for acute respiratory failure: "real life" experience in the emergency department. Emerg Med J 2005;22(11):772-777.

17. Wood KA, Lewis L, Von Harz B, Kollef MH. The use of noninvasive positive pressure ventilation in the emergency department: results of a randomized clinical trial. Chest 1998;113(5):1339-1346.

18. Heyland DK, Muscedere J, Drover J, Jiang X, Day AG, Canadian Critical Care Trials Group. Persistent organ dysfunction plus death: a novel, composite outcome measure for critical care trials. Crit Care 2011;15(2):R98.

19. Higgins TL, Teres D, Copes WS, Nathanson BH, Stark M, Kramer AA. Assessing contemporary intensive care unit outcome: an updated mortality probability admission model (MPM0-III). Crit Care Med 2007;35(3):827-835.

20. Quan H, Li B, Couris CM, Fushimi K, Graham P, Hider P, et al. Updating and validating the Charlson comorbidity index and score for risk adjustment in hospital discharge abstracts using data from 6 countries. Am J Epidemiol 2011;173(6):676-682.

21. Elie-Turenne MC, Hou PC, Mitani A, Barry JM, Kao EY, Cohen JE, et al. Lung injury prediction score for the emergency department: first step towards prevention in patients at risk. Int J Emerg Med 2012;5(1):33

22. Azevedo LCP, Caruso P, Silva UVA, Torelly AP, Silva E, Rezende E, et al. Outcomes for patients with cancer admitted to the ICU requiring ventilatory support: results from a prospective multicenter study. Chest 2014;146(2):257-266.

23. Piroddi IMG, Barlascini C, Esquinas A, Braido F, Banfi P, Nicolini A. Non-invasive mechanical ventilation in elderly patients: a narrative review. Geriatr Gerontol Int 2017;17(5):689-696.

24. Scala R. Challenges on non-invasive ventilation to treat acute respiratory failure in the elderly. BMC Pulm Med 2016;16(1):150.

25. Ozyilmaz E, Ugurlu AO, Nava S. Timing of noninvasive ventilation failure: causes, risk factors, and potential remedies. BMC Pulm Med 2014; $14: 19$

26. Penuelas O, Esteban A. Noninvasive ventilation for acute respiratory failure: the next step is to know when to stop. Eur Respir J 2018; 52(2): 1801185

27. Liu Y, An Z, Chen J, Liu Y, Tang Y, Han Q, et al. Risk factors for noninvasive ventilation failure in patients with post-extubation acute respiratory failure after cardiac surgery. J Thorac Dis 2018;10(6): 3319-3328. 


\section{NIV Use IN THE EMERGENCY DePARTMENT}

28. Hill NS, Brennan J, Garpestad E, Nava S. Noninvasive ventilation in acute respiratory failure. Crit Care Med 2007;35(10):2402-2407.

29. Walkey AJ, Wiener RS. Use of noninvasive ventilation in patients with acute respiratory failure, 2000-2009: a population-based study. Ann Am Thorac Soc 2013;10(1):10-17.

30. Ambrosino N, Vagheggini G. Noninvasive positive pressure ventilation in the acute care setting: where are we? Eur Respir J 2008; 31(4):874-886.

31. Mehta AB, Douglas IS, Walkey AJ. Evidence-based utilization of noninvasive ventilation and patient outcomes. Ann Am Thorac Soc 2017;14(11):1667-1673.
32. Frohlich S, Murphy N, Doolan A, Ryan O, Boylan J. Acute respiratory distress syndrome: underrecognition by clinicians. J Crit Care 2013;28(5):663-668.

33. Fan E, Brodie D, Slutsky AS. Acute respiratory distress syndrome: advances in diagnosis and treatment. JAMA 2018;319(7): 698-710.

34. Bauer PR, Kumbamu A, Wilson ME, Pannu JK, Egginton JS, Kashyap $\mathrm{R}$, et al. Timing of intubation in acute respiratory failure associated with sepsis: a mixed methods study. Mayo Clin Proc 2017;92(10):15021510. 